\title{
A constituição do sujeito contemporâneo do consumo: um desafio para a educação ambiental
}

\author{
Andresa Silva da Costa Mutz* \\ Paula Corrêa Henning ${ }^{* *}$ \\ Bárbara Hees Garré****
}

\begin{abstract}
Resumo
O artigo identifica a constituição dos sujeitos contemporâneos do consumo como um importante desafio para a Educação Ambiental. Aponta para a emergência de uma expertise do consumo que se vale com muita eficiência das verdades estatísticas para ensinar que determinados comportamentos de consumo são aceitáveis; e outros, não. Fragmentos do documento intitulado Agenda 21, elaborado durante importante evento realizado nos anos de 1990 no Brasil, em que diversos líderes e instituições mundiais discutiram o destino do Planeta Terra, foram selecionados como material empírico da investigação. Procedeu-se a uma análise enunciativa inspirada no trabalho de Michel Foucault e seus leitores mais contemporâneos, como Rosa Fischer, Fabiana Amorim e Marisa Costa. Os resultados obtidos apontaram para o agenciamento dos sujeitos por meio do discurso do consumo consciente e consequente responsabilização dos consumidores pelo enunciado do risco ambiental, financeiro e social. O que faz dele muito mais um recurso de controle das condutas dos sujeitos, de modo a manter em funcionamento o sistema econômico em vigor, do que uma tomada de posição crítica ao modelo de consumo que tem causado prejuízos ao meio ambiente e à sociedade em geral.
\end{abstract}

Palavras-chave: Educação. Consumo. Educação Ambiental.

\footnotetext{
* Doutora em Educação pela Universidade Federal do Rio Grande do Sul (UFRGS). Professora do Instituto de Educação e do Programa de Pós-Graduação em Educação da Universidade Federal do Rio Grande (FURG).

** Doutora em Educação pela Universidade do Vale do Rio dos Sinos (UNISINOS). Professora do Instituto de Educação, do Programa de Pós-Graduação em Educação Ambiental e do Programa de Pós-Graduação em Educação em Ciências da Universidade Federal do Rio Grande ( FURG).

${ }^{* * *}$ Doutora em Educação pela Universidade Federal do Rio Grande (FURG). Professora do Departamento de Graduação e do Departamento de Pós-Graduação do Instituto Federal do Rio Grande do Sul (IFSUL).
} 


\section{As "verdades" sobre o consumo e meio ambiente na contemporaneidade}

As nações precisam dos consumidores para manter sua lógica produtivista e mercantilista em funcionamento. Proliferam as avaliações e medições em que o comportamento dos consumidores é perscrutado, tornando-os objeto de comparações e previsões estatísticas. Daí resulta uma multiplicidade de intervenções pautadas por complexas relações de poder, que intentam conduzir a conduta dos consumidores, aproximando-os de uma média de consumo e endividamento por indivíduo considerada "desejável” de modo a garantir a segurança do sistema capitalista em sua fase neoliberal. Uma expertise do consumo trabalha para estudar a regularidade dos fenômenos decorrentes do superendividamento e do hiperconsumo, tanto no que diz respeito aos impactos ambientais quanto aos seus efeitos sociais e econômicos.

Neste artigo, nosso interesse se centraliza no discurso que, na contemporaneidade, nos permite aceitar como verdade incondicional a necessidade ou mesmo a urgência de um consumo consciente para salvação do Planeta, das sociedades e das finanças pessoais, especialmente porque, como ensina Veyne (2011, p. 167), “o que é tido por verdadeiro se faz obedecer”. Com a ajuda de Foucault (2003, p. 14), temos entendido a verdade como "um conjunto de procedimentos regulados para a produção, a lei, a repartição, a circulação e o funcionamento dos enunciados”. Daí decorre que a verdade está sempre relacionada a sistemas de poder específicos que legitimam determinados saberes em detrimento de outros.

Uma das coisas que nos atrai no tipo de pesquisa que Foucault realizava é que "seus trabalhos mostram a importância de nos inquietarmos com o que nos sucede hoje" (FISCHER, 2011, p. 238). Por isso, levando em conta que nas relações de poder contemporâneas o alvo do controle é a população e que o centro da autoridade tem se disseminado ao longo de diferentes instituições, para além do Estado, considerando também o fato de que, por prevalecer a liberdade do indivíduo contemporâneo, emerge o desafio de conduzir a conduta de todos e de cada em um horizonte de escolhas possíveis, nesse artigo nos perguntamos acerca das condições de possibilidade que permitiram naturalizar-se, em uma sociedade intensamente convocada a exercer seu poder de compra através do consumo, um discurso marcado por um apelo para que nos voltemos ao consumo consciente.

Admitindo que "Governar [...] é estruturar o eventual campo de ação dos outros" (FOUCAULT, 1995, p. 245), interessamo-nos aqui pela vontade de saber e de poder que opera pela "verdade" do consumo consciente no governo da conduta dos consumidores na contemporaneidade.

Foi em Foucault (2008) e naqueles que com ele dialogam em suas pesquisas (DELEUZE, 1998; FISCHER, 2000, 2001, 2005, 2007, 2011; MARCELLO, 2005, 2009) que encontramos inspiração para eleger a opção teórico-metodológica de trabalho apta a mapear essas "verdades" 
acerca do consumo por meio de algumas ferramentas da análise do discurso do consumo consciente e os seus enunciados. Procuramos extrair das palavras, frases e proposições aquilo que está antes delas. Não aquilo que supostamente estaria por trás delas. Ou seja, procuramos na materialidade das palavras, naquilo que foi dito, atentar para os enunciados que, mesmo raros, permitiram a repartição e dispersão daqueles saberes por meio da multiplicação das palavras, frases e proposições. Na medida em que "não há possível nem virtual no domínio dos enunciados; nele tudo é real, e nele toda a realidade está manifesta: importa apenas o que foi formulado, ali, em dado momento, e com tais lacunas, tais brancos" (DELEUZE, 1998, p. 15).

\section{Consumo de risco ambiental, financeiro e social}

Se considerarmos que é na cultura que se dão as lutas por significação, levando em conta o que afirma Veiga-Neto (2004, p. 40): "Por que a cultura está imbricada indissoluvelmente com relações de poder, derivam dessas relações a significação do que realmente é relevante culturalmente para cada grupo", então podemos entender seu caráter pedagógico, na medida em que tais lutas e embates acabam conferindo legitimidade a determinados modos de ser sujeito em detrimento de outros. Assim, reiteramos, embora escape ao cotidiano formal escolarizado, este artigo possibilita o contato com espaços da cultura por onde circulam verdades e, portanto, também diz respeito ao modo como 'aprendemos' a ser sujeitos conforme modelos socialmente aceitos. Afinal, como argumenta Costa (2004, p. 77, grifo da autora) acerca do caráter pedagógico das práticas culturais, "quem tem o poder de narrar o outro, dizendo como está constituído, como funciona, que atributos possui, é quem dá as cartas de representação, ou seja, é quem estabelece o que tem ou não tem estatuto de "realidade"'.

Temos visto proliferar, na cultura contemporânea, narrativas que fazem referência ao consumo como um "problema”. Em campos de saber diversos, com ênfases específicas, acionando tecnologias bem particulares de governo dos consumidores. Ora como um problema planetário, ora como uma dificuldade pessoal, o que temos verificado no conjunto dos materiais analisados em nossas pesquisas é que o consumo está sendo inscrito, por meio de práticas discursivas, como um grande problema na contemporaneidade.

Considerando que "Os ideais de governo estão intrinsecamente ligados aos problemas ao redor dos quais ele circula, às falhas que ele procura retificar, às doenças que ele procura curar" (ROSE; MILLER, 2012, p.79), entendemos que a construção discursiva do consumo como um problema ambiental, econômico e social possa ser pensada como uma evidência da vontade de governar os sujeitos. O que explicaria a emergência, nas últimas décadas, não apenas de um 
conjunto de enunciados que assim o definem, mas também de um grupo de especialistas autorizados e de recursos de diagnóstico validados formando uma expertise do consumo.

Levando em conta o papel dessa expertise na condução da conduta dos consumidores brasileiros, importa problematizar o modo como operam as verdades proferidas por tais peritos na constituição dos sujeitos contemporâneos do consumo. Referimo-nos ao uso das avaliações, medições, registros e estatísticas para corroborar determinadas "verdades" acerca do comportamento de consumo e governar a conduta dos consumidores. Precisamente porque, como afirmam Traversini e Bello (2009, p. 137):

Conduzir, regular e normalizar uma população não requer unicamente a extração de saberes sobre ela - como o vem fazendo a antropologia, a psicologia social, a demografia, entre outros. Além disso, há necessidade de se produzirem registros sobre essa população, para propor, para acompanhar e para avaliar intervenções, quantificando os seus aspectos mais característicos e de interesse, formulando saberes para depois disponibilizá-los aos governos e às sociedades.

Os saberes produzidos por essa expertise do consumo e disponibilizados à população, em especial, aqueles que vemos circular na mídia televisiva, tem nos alertado quanto a existência de um tipo de consumo considerado de risco ambiental, financeiro e social: um comportamento de consumo que coloca em risco o equilíbrio das desigualdades, mantido a alto preço pelo capitalismo. Mas é preciso sublinhar, em relação à construção discursiva desse risco pressuposto por determinadas formas de consumo, que

[...] o termo risco não designa nem um acontecimento nem mesmo um tipo de acontecimento da realidade - os acontecimentos 'funestos' - mas um modo de tratamento específico de certos acontecimentos que podem suceder a um grupo de indivíduos, ou mais exatamente a valores ou capitais possuídos ou representados por uma coletividade de indivíduos, ou seja, por uma população. (EWALD, 1993, p. 88, grifos nossos).

Por isso, admite-se aqui o caráter social, datado, contingente daquilo que nossa sociedade tem considerado o que denominamos comportamentos de consumo de risco. É sempre preciso lembrar que "Não há risco que não seja social. Com efeito, é somente por sobre a extensão de uma população inteira que o risco se torna calculável. [...] A segurança só tem alcance perante grupos; passa pela socialização dos riscos. A segurança faz de cada um parte do todo" (EWALD, 1993, p. 96). E importa sublinhar ainda que aceitar o caráter social do risco implica aceitarmos igualmente o caráter social do tipo de intervenção que cada grupo resolverá fazer sobre determinado fenômeno, porque, como afirmam Traversini e Bello (2009, p.150),

A constituição de um local como sendo de risco depende do uso do saber estatístico, que minuciosamente descreve como e onde esse risco se encontra. O modo de intervir depende da racionalidade, ou melhor, do modo de ser do pensamento, para resolver os problemas sociais em determinada época histórica. 
É isso que estamos defendendo neste artigo: os modos como lidamos com os consumidores de risco em uma sociedade de consumo como esta em que vivemos são contingentes. Trata-se mesmo de um modo muito particular de intervenção sob a categoria consumo de risco, que nos tem permitido a) objetivar esses indivíduos tornando-os visíveis como problema político e b) propor estratégias de condução das suas condutas em direção àquilo que se acordou ser um comportamento de consumo adequado para o Planeta Terra e para o Capitalismo. É pelo cálculo da probabilidade de baixa no consumo decorrente do superendividamento que o discurso do consumo consciente ensina como endividar-se sem extrapolar a média e a manter a liquidez do sujeito consumidor no mercado. A estatística aponta para a possibilidade de derretimento das geleiras nos polos, conforme padrões matemáticos de acompanhamento dos níveis do mar, ensinando-nos a separar o lixo e a reciclá-lo. Os níveis de violência tabulados nos ensinam a preferir produtos certificados por organismos do Estado, atestando sua legalidade.

Nas constantes referências a uma suposta crise ambiental e nas recorrentes representações das crises econômicas verificadas no material empírico desta pesquisa, a função do consumo consciente seria "reduzir" os impactos do consumo e seus fenômenos contemporâneos - como o superendividamento e o hiperconsumo, por exemplo - o que nos levou a entendê-lo, no contexto desta pesquisa, como uma estratégia para se alcançar o equilíbrio tolerável (LAZZARATO, 2011) e o gerenciamento de escassez (PASSETI, 2013) no sistema capitalista, em sua versão mais contemporânea, pois,

Na lógica neoliberal, todas as proteções contra os riscos, todas as instituições da propriedade social são dispositivos que devem funcionar no mínimo (salário mínimo, velhice mínima, rendimento mínimo, etc.), e o mínimo tem um sentido político, pois ele define um limiar para além do qual existe um risco de 'guerra civil', de ruptura da paz social. (LAZZARATO, 2011, p. 51).

Pensar em programas que educam para o consumo consciente é, nesse sentido, agir para manter a crise em patamares mínimos. Significa instrumentalizar os consumidores a continuarem comprando, mas o mínimo; a continuarem endividando-se, mas o mínimo. Por isso, no material que analisamos, a informação e a formação do consumidor eram narrados como atributos desejáveis aos indivíduos que consomem. O que se está encorajando é a autonomia e a consequente responsabilização dos sujeitos por sua segurança em meio a uma crise ambiental, financeira e social.

\section{Governar pelo consumo}

No que diz respeito ao consumo, esse estudo se inscreve em uma vertente teórica que congrega pensadores como Frederic Jamenson, Zygmunt Bauman, Jean Baudrillard, entre outros, 
que entendem a Cultura do Consumo como marca distintiva da Pós-Modernidade. Tal noção nos permite procurar, na contingência histórica, os tipos de saberes que sustentam as relações de poder e tornam possíveis a emergência do discurso do consumo consciente, especialmente nesse tempo, como em nenhum outro.

Não pensamos que seja possível apontarmos o consumo como a única marca distintiva da formação atual das sociedades ocidentais neoliberais. No entanto, sublinhamos que é muito singular o modo como o consumo tem sido (re)significado sob a racionalidade neoliberal. Interessamo-nos, pois, neste estudo, por autores que, com suas pesquisas, remetam-se a tal contingência, visto que a partir deles é que procuramos mapear também o modo particular com que o consumo de tipo consciente emerge no discurso que atravessa os materiais empíricos desta investigação.

Nesse sentido, dialogamos também com Featherstone (1995), que explica ter percebido seus estudos sobre a Cultura do Consumo como um deslocamento da noção de consumo como valor econômico - marcado por princípios em que se celebra a moderação e o gerenciamento da escassez -, à qual se sobrepõe uma outra concepção de consumo, que, na contemporaneidade, tem posto em circulação a consigna do consumo como excesso. Segundo o autor, essas duas noções não se excluem, apenas se deslocam e se sobrepõem em movimentos decorrentes das demandas de cada sociedade. Assim, convivendo ambas,

[...] a cultura de consumo na atualidade não representa nem um lapso do controle, nem a instituição de controles mais rígidos; mas antes, a corroboração dos controles por uma estrutura gerativa subjacente flexível, capaz de lidar ao mesmo tempo com o controle formal e o descontrole, bem como facilitar uma troca de marchas confortável para ambos. (FEATHERSTONE, 1995, p. 48).

Ou seja, à ampliação das práticas de consumo voltadas para a satisfação de prazeres e desejos, soma-se a evocação de valores como equilíbrio, racionalidade, planejamento, como marcadores de um tipo de sujeito de consumo: o consumidor consciente, que emerge estrategicamente nesses dias nossos dias, e não em outros. Passemos ao material empírico para problematizarmos os modos como acionamos um certo sujeito consumidor.

\section{A produtividade do enunciado "É preciso comprar bem, para comprar sempre"}

O Estado brasileiro disponibiliza, no site do Ministério do Meio Ambiente, a consulta à Agenda 21(ONU, 1995), um dos mais importantes documentos produzidos em nível global acerca das ações locais a serem adotadas como estratégia para "salvação do planeta" frente aos riscos ambientais. O documento está acompanhado no site por uma breve apresentação, onde lemos:

A Organização das Nações Unidas - ONU realizou, no Rio de Janeiro, em 1992, a Conferência das Nações Unidas sobre o Meio Ambiente e o Desenvolvimento (CNUMAD). A CNUMAD é mais conhecida como Rio 92, referência à cidade que 
a abrigou, e também como "Cúpula da Terra" por ter mediado acordos entre os Chefes de Estado presentes. 179 países participantes da Rio-92 acordaram e assinaram a Agenda 21 Global, um programa de ação baseado num documento de 40 capítulos, que constitui a mais abrangente tentativa já realizada de promover, em escala planetária, um novo padrão de desenvolvimento, denominado "desenvolvimento sustentável". O termo "Agenda 21 " foi usado no sentido de intenções, desejo de mudança para esse novo modelo de desenvolvimento para o século XXI. (BRASIL, [2008?], grifos nossos).

O consumo está pressuposto como problema global no vocábulo "desenvolvimento", que implica, na configuração mais contemporânea do capitalismo, não apenas a produção, mas também as relações de mercado e, cada dia mais intensamente, as relações de consumo ${ }^{1}$. Nesse sentido, a Agenda 21 aponta para um problema de proporções planetárias que exige a organização de programas a serem implantados pelos diferentes países que a acordaram a fim de se construir como um novo modelo de produção e consumo. De fato, entre os 40 capítulos que compõem o documento, dividido em quatro seções (1. Dimensões sociais e econômicas; 2. Conservação e gestão dos recursos para o desenvolvimento; 3. Fortalecimento do papel dos grupos principais; 4. Meios de implementação), apresenta-se na primeira seção, no capítulo quarto, a questão do consumo e sua relação com o destino do Planeta.

Intitulado Mudança dos padrões de consumo, o capítulo constrói o argumento de que a pobreza a os problemas ambientais são faces de uma mesma moeda. Resultam dos desequilíbrios econômicos e ambientais no que concerne à produção e consumo de bens, como vemos no excerto transcrito abaixo:

A pobreza e a degradação do meio ambiente estão estreitamente relacionadas. Enquanto a pobreza tem como resultado determinados tipos de pressão ambiental, as principais causas da deterioração ininterrupta do meio ambiente mundial são os padrões insustentáveis de consumo e produção, especialmente nos países industrializados. Motivo de séria preocupação, tais padrões de consumo e produção provocam o agravamento da pobreza e dos desequilíbrios (ONU, 1995, p. 33, grifos nossos).

Assim, o documento promete que se a questão da produção e do consumo for tratada corretamente, ou seja, se os países se submeterem ao programa da Agenda 21 e cumprirem as prescrições que lhes são feitas no acordo junto às suas populações, então alcançaremos não apenas a solução para o processo de degradação do Planeta, com o equilíbrio das relações econômicas, mas também para o fenômeno da pobreza, com a diminuição dos desequilíbrios sociais.

A promessa do extermínio da pobreza não é uma exclusividade da Modernidade. Na passagem do feudalismo para o capitalismo, já se anunciava a possibilidade de se alcançar o fim das injustiças que marcavam, até aquele momento, as relações entre senhores e servos. Porém, acreditava-se, à época do nascimento da Modernidade, que o cumprimento da promessa estava condicionado às transformações políticas necessárias para romper com o Antigo Regime e 
possibilitar a liberdade plena aos que, por natureza, ou melhor, por nascimento, eram considerados servos. Liberdade política para construírem sua condição social. Ora, o capitalismo garantiu essa liberdade para uma boa parcela da população mundial organizada sob o regime político democrático, mas, mesmo passados aproximadamente dois séculos desde seu aparecimento - se considerarmos a Revolução Industrial no século XIX como marco de sua emergência -, a promessa ainda não se cumpriu. Portanto, a novidade histórica que faz do discurso do consumo consciente enunciado no fragmento da Agenda 21 um acontecimento ${ }^{2}$, é que a promessa do fim da pobreza agora requer como condição para seu cumprimento uma transformação no modelo de produção e consumo: que se compre bem, a fim de se comprar sempre.

Nos dois fragmentos que apresentamos a seguir, destacamos a singularidade histórica da promessa do fim da pobreza, condicionada à transformação nos modelos de produção e de consumo. Como se pode verificar, por meio de "[...] uma linguagem que apela para o poder da verdade" (ROSE; MILLER, 2012, p. 88), o documento legitima a necessidade de ampliação do que denominamos como as expertises do consumo para compreender e tratar os problemas decorrentes do tipo de consumo que estamos praticando na contemporaneidade:

Especial atenção deve ser dedicada à demanda de recursos naturais gerada pelo consumo insustentável, bem como ao uso eficiente desses recursos, coerentemente com o objetivo de reduzir ao mínimo o esgotamento desses recursos e de reduzir a poluição. Embora em determinadas partes do mundo os padrões de consumo sejam muito altos, as necessidades básicas do consumidor de um amplo segmento da humanidade não estão sendo atendidas. Isso se traduz em demanda excessiva e estilos de vida insustentáveis nos segmentos mais ricos, que exercem imensas pressões sobre o meio ambiente. Enquanto isso os segmentos mais pobres não têm condições de ser atendidos em suas necessidades de alimentação, saúde, moradia e educação. A mudança dos padrões de consumo exigirá uma estratégia multifacetada centrada na demanda, no atendimento das necessidades básicas dos pobres e na redução do desperdício e do uso de recursos finitos no processo de produção (ONU, 1995, p. 33-34, grifos nossos).

Malgrado o reconhecimento crescente da importância dos problemas relativos ao consumo, ainda não houve uma compreensão plena de suas implicações. Alguns economistas vêm questionando os conceitos tradicionais do crescimento econômico e sublinhando a importância de que se persigam objetivos econômicos que levem plenamente em conta o valor dos recursos naturais. Para que haja condições de formular políticas internacionais e nacionais coerentes é preciso aumentar o conhecimento acerca do papel do consumo relativamente ao crescimento econômico e à dinâmica demográfica (ONU, 1995, p. 34, grifos nossos).

A noção de consumidor consciente, já naturalizada em nossos dias (MUTZ, 2013), emergiu ${ }^{3}$ nos idos dos anos de 1990, quando, quase ao final do capítulo relacionado ao consumo, vemos a expressão "público consumidor mais consciente", conforme fragmento abaixo:

O recente surgimento, em muitos países, de um público consumidor mais consciente do ponto de vista ecológico, associado a um maior interesse, por parte de algumas indústrias, em fornecer bens de consumo mais saudáveis 
ambientalmente, constitui acontecimento significativo que deve ser estimulado. Os Governos e as organizações internacionais, juntamente com o setor privado, devem desenvolver critérios e metodologias de avaliação dos impactos sobre o meio ambiente e das exigências de recursos durante a totalidade dos processos e ao longo de todo o ciclo de vida dos produtos. Os resultados de tal avaliação devem ser transformados em indicadores claros para informação dos consumidores e das pessoas em posição de tomar decisões. (ONU, 1995, p. 37, grifos nossos).

Nossa intenção aqui não é apontar as origens do termo consumidor consciente em um retorno ao seu momento fundante, através do qual fosse possível recuperar seu verdadeiro sentido, hoje, supostamente, deturpado. Antes, desejamos neste exercício de análise ir demarcando a estreiteza e singularidade dessa noção de consumidor como agente de transformação social, ambiental e econômica, buscando elementos que permitam determinar as condições de existência (FOUCAULT, 2008) do enunciado que torna visível e dizível o consumo consciente. Finalmente, no último excerto da Agenda 21 que compartilhamos, temos a referência à tarefa dos Estados ${ }^{4}$ :

Além disso, os Governos também devem estimular o surgimento de um público consumidor informado e auxiliar indivíduos e famílias a fazer opções ambientalmente informadas das seguintes maneiras: (a) Com a oferta de informações sobre as consequências das opções e comportamentos de consumo, de modo a estimular a demanda e o uso de produtos ambientalmente saudáveis; (b) Com a conscientização dos consumidores acerca do impacto dos produtos sobre a saúde e o meio ambiente por meio de uma legislação que proteja o consumidor e de uma rotulagem com indicações ecológicas; (c) Com o estímulo a determinados programas expressamente voltados para os interesses do consumidor, como a reciclagem e sistemas de depósito/restituição. (ONU, 1995, p. 37, grifos nossos).

A solução para o problema do consumo pressupõe auxiliar os indivíduos a "fazer opções ambientalmente informadas" e "por meio da conscientização", como lemos acima. Assim, se "governa à distância" com as escolhas dos cidadãos (ROSE, 1998). E, paralelamente a essa construção discursiva de um "eu" consumidor que escolhe e, cada vez mais, tem a obrigação de escolher, se não quiser ser acusado de não ser um consumidor consciente, vai se constituindo também a noção de que o "meu" consumo ou minhas escolhas de consumo são responsáveis pelos meus problemas, pelos problemas da minha família, pelos problemas da economia nacional, pelos problemas do mundo. Assim, afirma Bauman (2008a, 113):

As noites que se seguem aos dias de rotina obrigatória são cheias de sonhos de se emancipar das restrições. As noites subsequentes aos dias de escolha obrigatória são cheias de sonhos de emancipar-se da responsabilidade.

Emancipar-se da responsabilidade pelo derretimento das calotas polares, pois escolhi usar a mangueira de água para varrer a calçada. Emancipar-se da responsabilidade pela alta dos juros na economia, porque decidi usar novamente neste ano o limite do cheque especial. Emancipar-me da responsabilidade por aquela criança que pede esmolas no sinal de trânsito, porque decidi não 
colaborar com a empresa voluntária, que recolhe seus impostos em favor de uma Organização não Governamental (OnG).

\section{Considerações finais}

Segundo Larrosa (1994, p. 36, grifos do autor), no processo de subjetivação, “[...] o mais importante não é que se aprenda algo 'exterior', um corpo de conhecimentos, mas que se elabore ou reelabore alguma forma de relação reflexiva do 'educando' consigo mesmo". O que destacamos aqui é que, mais do que um conjunto de conhecimentos acerca da educação ambiental e da educação financeira, o discurso do consumo consciente opera na subjetivação dos indivíduos para que se admitam como sujeitos aprendentes e na instrumentalização deles de modo que tenham condições de administrarem-se a si mesmos.

Esse "admitir-se" como sujeito do consumo na condição de aprendente não aparece nos materiais analisados nesta pesquisa como resultado de uma obrigação legal ou pelo uso da violência, por exemplo. O assujeitamento dos consumidores se dá pela responsabilização. No interior do discurso do consumo consciente, um conjunto de verdades quase "proféticas" atesta as catastróficas consequências pessoais, coletivas, planetárias implicadas nos modos inadequados de consumir. Assim, responsabilizados por seus atos de consumo, os sujeitos convivem com a culpa e o desejo de extirpá-la.

Aprender a ser um bom consumidor e, em especial, um consumidor consciente, me possibilitaria ajudar a eliminar as desigualdades sociais no País e no Mundo, participando de um modelo produtivo mais sustentável; nessa condição, poderia também garantir a realização de meus sonhos ao assumir o controle da minha vida financeira; e, caso fosse uma necessidade, seria possível até restaurar minha saúde financeira adotando hábitos simples, como pensar antes de fazer cada compra.

Na contingência da estabilização monetária do País e na facilitação do acesso ao crédito, conserva-se a necessidade de ensejar o consumo, mas emerge a urgência de também controlá-lo. Não por qualquer outro motivo, senão pela manutenção do equilíbrio mensurado através da análise estatística das médias de consumo desejáveis para a população, de maneira que "[...] o cidadão ativo deve acrescentar às suas obrigações a necessidade de adotar uma relação calculadora pessoal prudente ao destino, agora concebido em termos de perigos calculáveis e de riscos previsíveis" (ROSE; MILLER, 2012, p. 256).

O que indicamos até aqui é que, em meados da década de 1990, o consumo foi vinculado à cidadania pela proliferação de enunciados de um discurso que pedagogicamente nos ensina a respeito do potencial de transformação ambiental, social e econômico pressuposto por nossos atos 
de consumo. A responsabilização do consumidor resultou na sua culpabilização, e multiplicaram-se também práticas de intervenção na vida daqueles indivíduos a quem se convencionou denominar "doentes do consumo", a fim de lhes restaurar a "saúde financeira", e os instrumentalizar para se manterem "saudáveis" por mais tempo. Disso decorre o caráter pedagógico do discurso do consumo consciente, pois, como afirma Camozzato (2012, p. 77), "há vontade de pedagogia, posto que há vontade de conduzir sujeitos".

Do ponto de vista econômico, isso significa dizer que o cidadão consumidor aprendiz busca se educar para responder as exigências de uma economia de competição, tornando-se ele próprio mercadoria (BAUMAN, 2008b). Do ponto de vista social, o cidadão consumidor aprendiz procura se educar para mais bem escolher, pois está convencido de que as escolhas que faz são responsáveis por todo o bem ou por todo o mal que lhe sobrevém.

Assim, ao contrário do que é prometido ao consumidor contemporâneo acerca de sua participação cidadã no consumo consciente, o que percebemos neste trabalho de pesquisa foi um esvaziamento da noção de cidadania pela neutralização de seu potencial de construção de novas realidades coletivas pela participação individual. Não podemos negar o fato de que a promessa do consumo consciente coloca no horizonte desejável dos sujeitos um ideal de transformação social, mas isso, a nosso ver, não implica necessariamente a construção de novas realidades; pressupõe, isto sim, apenas o gerenciamento da escassez para manutenção e "reparos" na forma do sistema capitalista frente ao agravamento das desigualdades sociais.

\section{NOTAS}

${ }^{1}$ Veiga-Neto (2000, p. 19) faz um apanhado das mudanças econômicas que caracterizaram o cenário pósmoderno e destaca que, no pós-guerra, a essencialização do mercado e a intensa diversificação das demandas do consumo foram duas importantes transformações que operaram em um "deslocamento do centro de gravidade do (capitalismo) da produção - cujo incremento era o grande objetivo do capitalismo do "tradicional' - para o produto - cuja circulação dependerá do mercado. É daí que resultou a própria reificação do mercado".

${ }^{2}$ Foucault (2003, p. 28) explica que a "As forças que se encontram em jogo na história não obedecem nem a uma destinação, nem a uma mecânica, mas ao acaso da luta. Elas não se manifestam como formas sucessivas de uma intenção primordial; como também não têm o aspecto de um resultado. Elas aparecem sempre na área singular do acontecimento."

${ }^{3}$ Estamos considerando essa afirmação a partir da tese de Andresa Mutz (2013) nas referências desse artigo.

${ }^{4} \mathrm{O}$ uso da inicial maiúscula na expressão 'Governos', permite pensar que o que se quer nomear com ele são os países ou Estados coautores e participantes na formulação do documento Agenda 21 Global.

\section{REFERÊNCIAS}

BAUMAN, Zygmunt. Medo Líquido. Tradução: Carlos Alberto Medeiros. Rio de Janeiro: Jorge Zahar, 2008a.

BAUMAN, Zygmunt. Vida para consumo: a transformação das pessoas em mercadorias. Tradução: Carlos Alberto Medeiros. Rio de Janeiro: Jorge Zahar, 2008b. 
BRASIL. Ministério do Meio Ambiente. Agenda 21. Ministério do Meio Ambiente. Página Institucional. Brasília, DF, [2008?]. Disponível em: <http://www.mma.gov.br/responsabilidadesocioambiental/agenda-21>. Acesso em: 2 jun. 2017.

COSTA, Marisa Vorraber. Mídia, Magistério e Política Cultural. In: Estudos culturais em educação: mídia, arquitetura, brinquedo, biologia, literatura, cinema... Porto Alegre: UFRGS, 2004, p.73-79.

DELEUZE, Gilles. Foucault. Tradução: Cláudia Sant’Anna Martins. São Paulo: Brasiliense, 1998.

EWALD, François. Foucault, a Norma e o Direito. Tradução: António Fernando Cascais. Lisboa: Vega, 1993.

FEATHERstone, Mike. Cultura de Consumo e Pós-modernismo. Tradução: Julio Assis Simões. São Paulo: Studio Nobel, 1995.

FISCHER, Rosa Maria Bueno. "Técnicas de si” na TV: a mídia se faz pedagógica. Educação Unisinos, São Leopoldo, v.4, n.7, p.111-139, 2000.

FISCHER, Rosa Maria Bueno. Foucault e a análise do Discurso em Educação. Cadernos de Pesquisa. n.114, p.197-223, nov. 2001.

FISCHER, Rosa Maria Bueno. Mídia e Juventude: Experiências do Público e do Privado na Cultura. Caderno CEDES, Campinas, v. 25, n.65, p. 43-58, jan./abr. 2005.

FISCHER, Rosa Maria Bueno. A paixão de trabalhar com Foucault. In: COSTA Marisa Vorraber (Org.). Caminhos Investigativos I: Novos Olhares em Educação. 3. ed. Rio de Janeiro: Lamparina, 2007.

FISCHER, Rosa Maria Bueno. Desafios de Foucault à Teoria Crítica em Educação. In: APPLE, Michel; AU, Wayne; GANDIN, Luís Armando (Orgs.). Educação Crítica: análise internacional. Tradução: Vinícius Figueira. Porto Alegre: Artmed, 2011. p. 233-247.

FOUCAULT, Michel. O sujeito e o poder. In: DREYFUS, Hubert; RABINOW, Paul. Michel Foucault (Orgs.). Uma trajetória filosófica: para além do estruturalismo e da hermenêutica. Rio de Janeiro: Forense Universitária, 1995. p. 231-249.

FOUCAULT, Michel. Microfísica do Poder. Rio de Janeiro: Graal, 2003.

FOUCAUlt, Michel. A Arqueologia do Saber. Tradução: Luiz Felipe Baeta Neves. Rio de Janeiro: Forense Universitária, 2008.

LARROSA, Jorge. Tecnologias do Eu e a Educação. In: SILVA, Tomaz Tadeu (Org.). O Sujeito da Educação: Estudos Foucaultianos. Petrópolis: Editora Vozes, 1994, p. 35-86.

LAZZARATO, Maurizio. O governo das desigualdades: crítica da insegurança neoliberal. Tradução: Renato Abramowicz Santos. São Carlos: EdUFSCar, 2011.

MARCELLO, Fabiana de Amorim. Enunciar-se, organizar-se, controlar-se: modos de subjetivação feminina no dispositivo da maternidade. Revista Brasileira de Educação. n. 29, p. 139-152, maio/ago. 2005. 
MARCELLO, Fabiana de Amorim. Sobre os modos de produzir sujeitos na cultura: o conceito de dispositivo em questão. Currículo sem fronteiras, v. 9, n. 2, p. 226-241, jul./dez., 2009.

MUTZ, Andresa Silva da Costa. A constituição do sujeito contemporâneo do consumo: aprender a comprar bem, para comprar sempre. 2013. 108f. Tese (Doutorado em Educação) - Universidade Federal do Rio Grande do Sul, Faculdade de Educação, Programa de Pós-Graduação em Educação, Porto Alegre, RS/BR, 2013. $108 \mathrm{f}$.

ORGANIZAÇÃO DAS NAÇÕES UNIDAS (ONU). Agenda 21. Conferência das Nações Unidas sobre o Meio Ambiente e Desenvolvimento: de acordo com a Resolução no 44/228 da Assembleia Geral da ONU, de 22-12-89, estabelece uma abordagem equilibrada e integrada das questões relativas a meio ambiente e desenvolvimento. Tradução: Ministério das Relações Exteriores, Divisão do Meio Ambiente, com a colaboração do Programa das Nações Unidas para o Meio Ambiente - PNUMA. Brasília: Câmara dos Deputados, Coordenação de Publicações, 1995. Série Ação Parlamentar, $\quad \mathrm{n}^{\circ} \quad 56 . \quad$ Disponível em: <http://www.onu.org.br/rio20/img/2012/01/agenda21.pdf>. Acesso em: 2 jun. 2017.

PASSETI, Edson. Transformações da biopolítica e emergência da ecopolítica. Revista Ecopolítica. São Paulo, n. 5, p. 4-63, 2013.

ROSE, Nikolas. Governando a alma: a formação do eu privado. In: SILVA, Tomaz T. (Org.) Liberdades Reguladas: a pedagogia construtivista e outras formas de governo do eu. Petrópolis: Vozes, 1998.

ROSE, Nikolas; MILLER, Peter. Governando o presente: gerenciamento da vida econômica, social e pessoal. Tradução: Paulo Ferreira Valério. São Paulo: Paulus, 2012.

TRAVERSINI, Clarice; BELLO, Samuel Edmundo L. O Numerável, o Mensurável e o Auditável: estatística como tecnologia para governar. Educação \& Realidade. V. 34, n. 2, p. 135-152. maio/ago. 2009.

VEIGA-NETO, Alfredo. Educação e governamentalidade neoliberal: novos dispositivos, novas subjetividades. In: Retratos de Foucault. PORTOCARRERO, Vera; Guilherme Castelo BRANCO (Orgs.). Rio de Janeiro: Nau, 2000. p. 179-215.

VEIGA-NETO, Alfredo. Michel Foucault e os Estudos Culturais. In: COSTA, Marisa V. (Org.) Estudos culturais em educação: mídia, arquitetura, brinquedo, biologia, literatura, cinema... 2. ed. Porto Alegre: UFRGS, 2004, p. 37-69.

VEYNE, Paul. Foucault: Seu pensamento, sua pessoa. Tradução: Marcelo Jacques de Morais. Rio de Janeiro: Civilização Brasileira, 2011. 
The constitution of the contemporary subject of consumption: a challenge for Environmental Education

\begin{abstract}
This article identifies the constitution of the contemporary subjects of consumption as an important challenge for the Environment Education. It indicates the emergence of a consumer expertise that, based on statistics facts, teach that particular consumption behaviors are acceptable and others are not. In this study, fragments of Agenda 21, a document produced during an important event held in Brazil in the 1990s with the participation of global leaders and organizations, were used as empirical material. An enunciative analysis was conducted, based on the work of Michel Foucault and his most contemporary readers, as Rose Fischer, Fabiana Amorim, and Marisa Costa. The results indicated the persuasion of the subjects through the discourse of conscious consumption and consequent accountability of consumers for environmental, financial and social risks. This was found to be a feature of control in order to keep the economic system in place functioning rather than a critical position to the consumption model that has caused harm to the environment and society in general.
\end{abstract}

Keywords: Education. Consumption. Environment Education.

\section{Andresa Silva da Costa Mutz}

E-mail: andresa.mutz@furg.br

\section{Paula Corrêa Henning}

E-mail: paula.c.henning@gmail.com

Bárbara Hees Garré

E-mail: barbaragarre@gmail.com

\section{La constitución del sujeto contemporáneo}

frente al consumo: un desafío para la Educación Ambiental

\section{Resumen}

El artículo identifica la constitución de los sujetos contemporáneos frente al consumo como un importante desafío para la Educación Ambiental. Apunta para la emergencia de una expertise del consumo que se utiliza, con mucha eficiencia, de las verdades estadísticas para enseñar que determinados comportamientos de consumo son aceptables $\mathrm{y}$ otros no. Fueron seleccionados, como material empírico de la investigación, fragmentos del documento titulado Agenda 21, éste elaborado durante importante evento realizado en los años de 1990 en Brasil cuando diversos líderes e instituciones mundiales discutieron el destino del Planeta Terra. Se realizó un análisis enunciativo inspirado en el trabajo de Michel Foucault y sus lectores más contemporáneos, como Rosa Fischer, Fabiana Amorim y Marisa Costa. Los resultados obtenidos apuntaron para la promoción de sujetos por medio del discurso de consumo consciente y por la responsabilidad de los consumidores a partir del riesgo ambiental, financiero y social, convirtiendo esto em un recurso de control de las conductas de los sujetos como modo de mantener en funcionamiento el sistema económico en vigor, en vez de una tomada de posición crítica al modelo de consumo que ha causado perjuicios al medio ambiente y a la sociedad en general.

Palabras clave: Educación. Consumo. Educación Ambiental.

Enviado em: 18/08/2014

Aprovado em: 16/02/2017 